\title{
Salt-finger driven enhancement of upper ocean nutrient supply
}

\author{
A. Oschlies, H. Dietze, and P. Kähler \\ Institut für Meereskunde and der Universität Kiel, Germany \\ Received 4 September 2003; accepted 21 October 2003; published 6 December 2003.
}

[1] In the subtropics, estimates of upper-ocean nitrate supply by turbulent mixing have been found insufficent to balance estimated nutrient loss through organic-matter export. Most mixing-rate estimates as well as numerical turbulence closure schemes commonly employed in numerical models have, however, neglected salt-finger induced mixing. Here we examine the potential contribution of salt-finger induced mixing to nutrient fluxes. Our model results suggest that salt-fingering instabilities generate substantial nutrient fluxes (on average $0.03 \mathrm{~mol} \mathrm{~N} \mathrm{~m} \mathrm{yr}^{-1}$ ) which are of similar magnitude as fluxes associated with mechanically induced turbulence or with mesoscale eddies. Because saltfingering activity depends on the proportion of temperature versus salinity effects on stratification rather than on the stability of stratification itself, its sensitivity to climate change will differ from that of "ordinary" mixing processes and needs to be considered in the context of global change. INDEX TERMS: 4805 Oceanography: Biological and Chemical: Biogeochemical cycles (1615); 4842 Oceanography: Biological and Chemical: Modeling; 4845 Oceanography: Biological and Chemical: Nutrients and nutrient cycling; 4568 Oceanography: Physical: Turbulence, diffusion, and mixing processes; 1635 Global Change: Oceans (4203). Citation: Oschlies, A., H. Dietze, and P. Kähler, Saltfinger driven enhancement of upper ocean nutrient supply, Geophys. Res. Lett., 30(23), 2204, doi:10.1029/2003GL018552, 2003.

\section{Introduction}

[2] Over much of the subtropical oceans, the surface heat flux is directed into the ocean and evaporation exceeds precipitation. As a result, warm and salty surface waters form, which overlie colder and fresher water. This can give rise to salt-fingering instabilities: Because on molecular scales, heat diffuses more rapidly than salt, downward moving warm and salty blobs exchange heat faster than salt and become denser, which reinforces their initial downward motion. Upward moving cold and fresh blobs warm and become lighter, which reinforces their upward motion. The blobs can thus extend vertically and form interleaving fingers which transport salt, and also nutrients with molecular diffusivities similar to that of salt, more efficiently than heat. The net effect of salt fingers can be described by macroscopic mixing with larger mixing rates for salt and nutrients than for heat [Schmitt, 2003] (i.e., a relation opposite to that of the molecular diffusivities which are larger for heat). Whenever salt- fingering instabilities occur, this adds to turbulent mixing brought about by shear instabilities, wind stirring, or buoyancy fluxes. It is these latter "ordinary" mixing processes which are usually considered for estimates of nutrient supply to date.

[3] Observational evidence for salt fingering has, among other regions, been reported for the upper Central Water of the subtropical thermocline [Schmitt, 1981]. The necessary condition for its occurence can be described quantitatively in terms of the density ratio $R_{\rho}=\left(\alpha T_{z}\right) /\left(\beta S_{z}\right)$, where $\alpha$ and $\beta$ are the thermal expansion and haline contraction coefficients, and $T_{z}$ and $S_{z}$ are the vertical derivatives of the temperature and salinity fields, respectively [Washburn and Käse, 1987]. For $1<R_{\rho}<100$ the salt-fingering instability is theoretically permitted, but in an ocean constantly perturbed by internal-inertial motions substantial growth of the instabilities does usually not occur for $R_{\rho}$ much larger than 2 [Schmitt, 1979]. Figure 1a shows the average distribution of $R_{\rho}$ at the base of the euphotic zone (here chosen as $z=126 \mathrm{~m}$ ) of the North Atlantic as derived from monthly climatological temperature and salinity fields [Levitus and Boyer, 1994; Levitus et al., 1994], which for this depth level predict low values of $R_{\rho}$ and hence a strong preference for salt fingering in the eastern part of the subtropics. In the following, a numerical ecosystem-circulation model is employed to examine the significance of salt fingering for the nutrient supply to the euphotic zone.

\section{Model}

[4] A simple nitrogen-based four-compartment ecosystem model [Oschlies and Garçon, 1999] is coupled to a circulation model which covers the North Atlantic between $15^{\circ} \mathrm{S}$ and $65^{\circ} \mathrm{N}$ at a resolution of $1 / 3$ times $2 / 5$ degrees in meridional and zonal direction, respectively. The model is forced by monthly mean wind stress and heat flux fields derived from the years 1989 to 1993 of the reanalysis project carried out at the European Centre for Medium-Range Weather Forecasts (ECMWF) [Gibson et al., 1997]. The formulation of the non-solar part of the surface heat flux follows Haney [1971] with a fluxcorrection term that accounts for a heat-flux feedback from simulated surface temperature anomalies [Barnier et al., 1995]. Because precipitation fields were considered to be not yet reliable enough, freshwater fluxes were parameterized by restoring surface salinity to observed monthly means taken from the Levitus et al. [1994] atlas. While in previous experiments vertical mixing was parameterized as "ordinary" turbulent mixing using the closure scheme of Gaspar et al. [1990], the present model version additionally includes salt-finger induced mixing. Its parameterisation proposed by Zhang et al. [1998] is in 

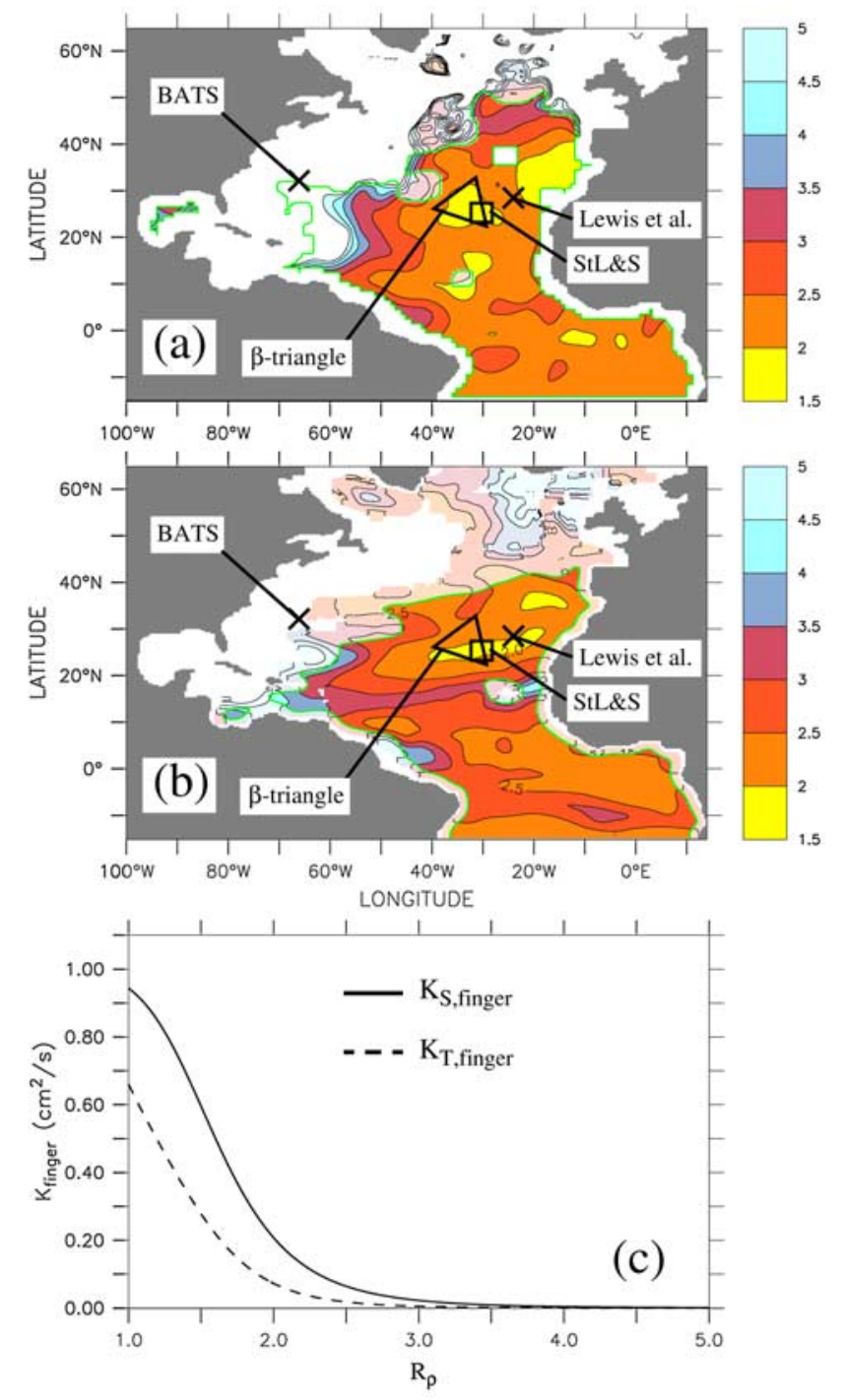

Figure 1. Density ratio $R_{\rho}=\left(\alpha T_{z}\right) /\left(\beta S_{z}\right)$ at the base of the euphotic zone $(z=126 \mathrm{~m})$. Annual mean of $R_{\rho}$ values computed (a) from monthly climatological temperature [Levitus and Boyer, 1994] and salinity [Levitus et al., 1994] fields and (b) simulated by the ocean circulation model, whenever warm and salty water overlies colder and fresher water (i.e., $R_{\rho}>1$ ). The area in which this criterion is satisfied all year round is enclosed by the green contour and displays the more intense colouring. (c) Salt-finger associated effective diffusivities for salt and nutrients, $K_{S, \text { finger }}$, and temperature, $K_{T, \text { finger }}$, according to the saltfingering parameterisation of Zhang et al. [1998] employed in the circulation model. For $R_{\rho}>1$, lowest $R_{\rho}$ values are associated with largest salt-finger induced diffusivities. Because the relation is non-linear, average salt-finger induced diffusivities cannot be computed from average $R_{\rho}$ values.

agreement with results from an elaborate analysis of microstructure measurements in the subtropical North Atlantic [St. Laurent and Schmitt, 1999] and was also found to perform well when applied to standard hydrographic measurements [Dietze et al., 2003]. For $R_{\rho}=2$, salt-finger associated diffusivities for salt and nutrients,
$K_{S, f i n g e r}$, are about $0.2 \mathrm{~cm}^{2} \mathrm{~s}^{-1}$ and increase to almost $1 \mathrm{~cm}^{2} \mathrm{~s}^{-1}$ when $R_{\rho}$ approaches unity (Figure 1c). For reference, mixing coefficients accounting for "ordinary" turbulent mixing are about $0.1 \mathrm{~cm}^{2} \mathrm{~s}^{-1}$ in the stratified thermocline [Ledwell et al., 1993; St. Laurent and Schmitt, 1999; Polzin et al., 1995].

\section{Results}

[5] Simulated density ratios $R_{\rho}$ reached after a 25-year spin-up period turn out to be in relatively good agreement with those observed (Figure 1) and also indicate the strong preference for salt fingering to occur at the base of the euphotic zone in the eastern part of the subtropical North Atlantic. The depth of lowest $R_{\rho}$ values increases west-southwestward from about $120 \mathrm{~m}$ near $25^{\circ} \mathrm{W}$ to more than $300 \mathrm{~m}$ near the Caribbean Islands where observations have also confirmed intense salt-fingering activity [Schmitt et al., 1987]. In the eastern part of the subtropical North Atlantic, both model results and monthly climatological data reveal a pronounced seasonal cycle of $R_{\rho}$ values at depth levels down to about $200 \mathrm{~m}: R_{\rho}$ values reach minimum values of about 1.3 with associated salt-finger diffusivities of about $0.8 \mathrm{~cm}^{2} \mathrm{~s}^{-1}$ in winter and spring during and after the warm and salty mixed layer has reached its maximum depth. Mixed layer deepening supplies salt from the evaporative surface layer to the pycnocline. On mixed-layer shoaling during spring, immediate salt supply from the sea surface ceases and density ratios increase above 1.6 and salt-finger induced mixing rates become smaller than $0.5 \mathrm{~cm}^{2} \mathrm{~s}^{-1}$ within a period of about two months. A comparison of simulated salt-finger induced diffusivities with observational estimates shows particularly good agreement (within 15\%) when the time interval of model output and observations is the same (Table 1). Adding the salt-fingering parameterisation was found to result in a very small decrease of sea surface temperatures (on average by $0.01^{\circ} \mathrm{C}$ ) and salinities (by $0.004 \mathrm{psu}$ ) with associated changes in simulated heat input $\left(0.5 \mathrm{~W} \mathrm{~m}^{-2}\right)$ and evaporation minus precipitation $\left(0.03 \mathrm{~m} \mathrm{yr}^{-1}\right)$.

[6] Annual nitrate supply simulated by the coupled ecosystem-circulation model including the salt-fingering parameterisation of Zhang et al. [1998] is shown in Figure 2a. Over large parts of the subtropical North Atlantic the model suggests a two- to fivefold higher nutrient supply compared to the case without salt-finger induced mixing. At the individual subtropical sites marked in Figure 2, salt fingering accounts for up to $80 \%$ of the total nitrate supply (Table 1 ). Such values are within the bounds of an earlier re-assessment of microstructure data suggesting that observational estimates of diffusive nitrate supply be revised upward by up to a factor of six if salt fingering were the dominant mixing mechanism [Hamilton et al., 1989]. Averaged over the eastern part of the oligotrophic subtropical gyre $\left(45-20^{\circ} \mathrm{W}, 20-30^{\circ} \mathrm{N}\right)$, saltfinger induced nitrate supply in our model amounts to $0.03 \mathrm{~mol} \mathrm{~m}^{-2} \mathrm{yr}^{-1}$ (Figure $2 \mathrm{~b}$ ) and approximately doubles previous estimates of diffusive supply that did not take salt fingering into account [Oschlies, 2002a]. It is noteworthy that for this region the simulated nutrient supply by salt fingering is of similar size as that by 
Table 1. Salt-finger Induced Diffusivities and Nitrate Supply at $z=126 \mathrm{~m}$

\begin{tabular}{|c|c|c|c|c|}
\hline & $\begin{array}{c}\text { Lewis et al. } \\
(23 \mathrm{~W}, 28.5 \mathrm{~N})\end{array}$ & $\begin{array}{c}\text { StL\&S } \\
(31-26.8 \mathrm{~W}, 24-25.7 \mathrm{~N})\end{array}$ & $\begin{array}{c}\beta \text { triangle, } 30 \mathrm{~W} \\
(30 \mathrm{~W}, 24-31.5 \mathrm{~N})\end{array}$ & $\begin{array}{c}\text { BATS } \\
(65 \mathrm{~W}, 32.5 \mathrm{~N}) \\
\end{array}$ \\
\hline \multicolumn{5}{|c|}{ Salt-finger induced tracer diffusivities $\left(\mathrm{cm}^{2} \mathrm{~s}^{-1}\right)$} \\
\hline $\mathrm{K}_{\mathrm{S} \text {,finger }}(\mathrm{obs}, \mathrm{month})$ & $0.22^{\mathrm{a}}$ & $0.46^{\mathrm{b}}$ & $0.58^{\mathrm{c}}$ & \\
\hline $\mathrm{K}_{\mathrm{S} \text {, finger }}\left(\bmod , \overline{\text { month }}^{\mathrm{d}}\right.$ & $0.19^{\mathrm{a}}$ & $0.40^{\mathrm{b}}$ & $0.53^{\mathrm{c}}$ & \\
\hline $\mathrm{K}_{\mathrm{S}, \text { finger }}(\bmod , \overline{\mathrm{yr}})$ & 0.23 & 0.28 & 0.26 & 0.04 \\
\hline \multicolumn{5}{|c|}{ Nitrate fluxes $\left(\mathrm{mol} \mathrm{N} \mathrm{m}^{-2} \mathrm{yr}^{-1}\right)$} \\
\hline salt finger contr. ${ }^{\mathrm{e}}$ & 0.042 & 0.053 & 0.052 & 0.082 \\
\hline total supply & 0.062 & 0.065 & 0.067 & 0.465 \\
\hline
\end{tabular}

${ }^{\mathrm{a}}$ June, observational estimate from Hamilton et al. [1989].

${ }^{\mathrm{b}}$ April, observational estimate from St. Laurent and Schmitt [1999].

${ }^{\mathrm{c}}$ March, observational estimate from Dietze et al. [2003].

${ }^{\mathrm{d}}$ Model estimates of $\mathrm{K}_{\mathrm{S}, \text { finger }}(\overline{\mathrm{month}})$ are consistently lower than the observational estimates by some $10 \%$, indicating that our estimate of salt-finger induced nitrate supply may be slightly too low.

${ }^{\mathrm{e}}$ Difference between simulations with and without salt-fingering parameterisation (i.e., includes non-linear effects due to changes in density field and circulation)

mesoscale eddies which, so far, have received considerably more attention. [McGillicuddy et al., 1998; Oschlies and Garçon, 1998; Oschlies, 2002b].

\section{Discussion}

[7] Despite its substantial contribution to the upper-ocean nutrient supply in the North Atlantic subtropical gyre, salt fingering alone does not seem to be sufficient to close the gap between previous estimates of nitrate supply [Lewis et al., 1986] and export of organic matter in the eastern part of the subtropical North Atlantic [Jenkins, 1982]. Recent observations near $30^{\circ} \mathrm{W}$ show, however, that the apparent observational discrepancy can be reconciled when, in addition to salt-finger induced mixing, nitrogen fixation and the export of carbon-rich organic matter are considered [Kähler et al., High rates of nitrogen fixation and TOC subduction in the eastern subtropical North Atlantic, submitted manuscript.

[8] An interesting aspect of salt-finger induced mixing is its strong dependence on water mass properties as expressed in the density ratio, i.e., in the relative contributions of temperature and salinity to the vertical density gradient. When these water mass properties change in response to changing atmospheric forcing, salt-finger induced mixing will be affected in a different way than "ordinary" turbulent mixing which seems to be relatively insensitive to changes in water column properties [Polzin et al., 1995]. Present climate models, which do not take into account salt-finger induced mixing, tend to predict largest changes in mixing and nutrient supply over the next century to occur at high latitudes [Sarmiento et al., 1998]. However, temperatureand precipitation/evaporation-driven changes in the density ratios simulated by such models suggest substantial impacts on salt-fingering activity in low-latitude surface waters. For example, the Geophysical Fluid Dynamics Laboratory (GFDL) coupled climate model [Delworth et al., 2002] predicts a more than $30 \%$ decrease of the area with density ratios in the range $1<R_{\rho}<2$ at the base of the euphotic zone in the subtropical and tropical North Atlantic within this century. Such estimates are still uncertain, particularly as they are very sensitive to prognosed changes in precipitation patterns. Nevertheless, the peculiar, and so far in this context neglected, feature of different molecular diffu-

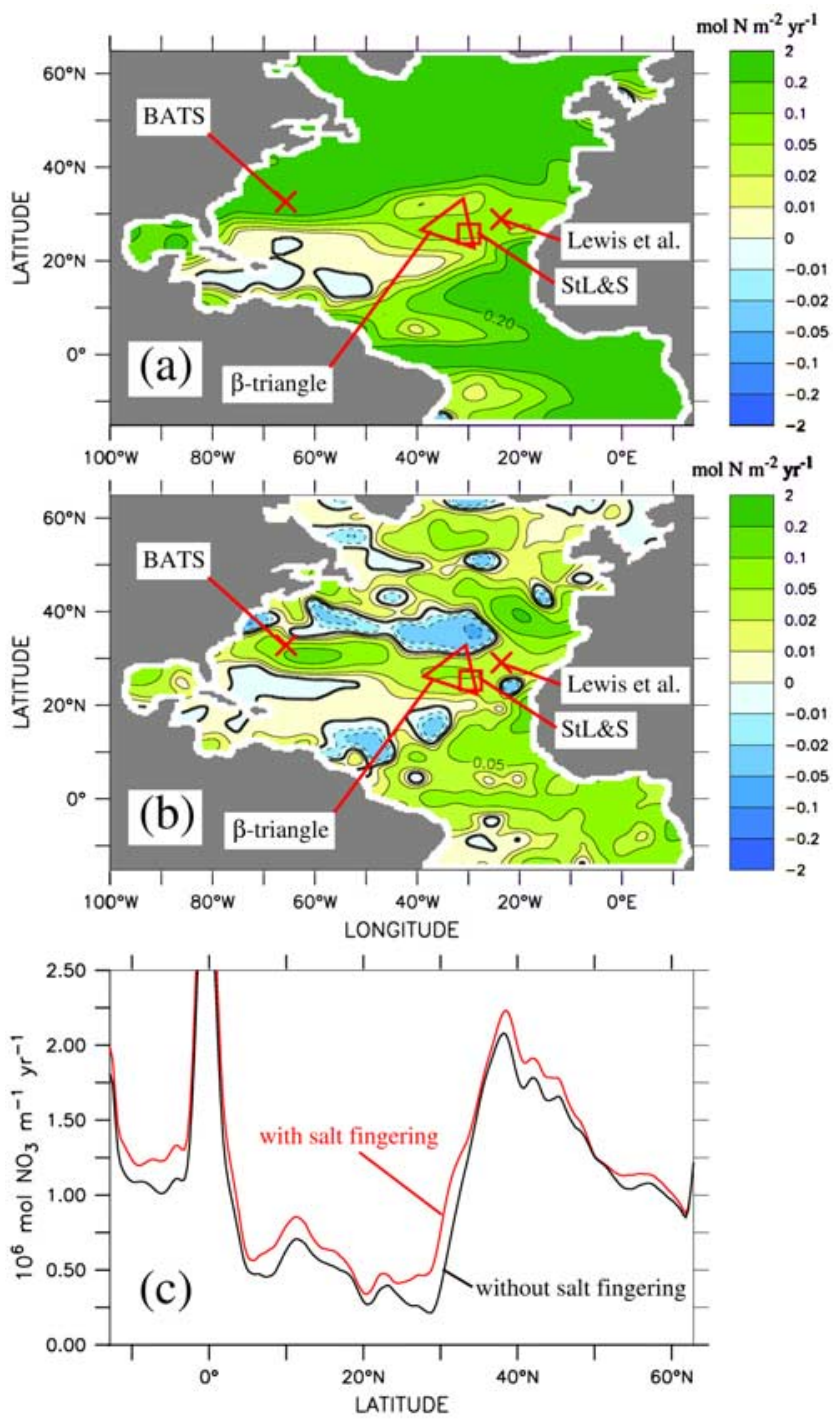

Figure 2. (a) Nitrate supply to the upper $126 \mathrm{~m}$ simulated by the experiment with salt-fingering parameterisation included. (b) Nitrate supply simulated by the experiment with salt-fingering parameterisation minus nitrate supply simulated by the experiment without this parameterisation. (c) Zonally integrated nitrate supply simulated by the experiment with (red line) and without (black line) salt fingering. 
sivities for temperature and salt will certainly contribute to anticipated large-scale changes in marine biological production.

[9] Acknowledgments. We acknowledge funding by the Deutsche Forschungsgemeinschaft and thank one anonymous reviewer for helpful and constructive comments.

\section{References}

Barnier, B., L. Siefridt, and P. Marchesiello, Surface thermal boundary condition for a global ocean circulation model from a three-year climatology of ECMWF analyses, J. Mar. Syst., 6, 363-380, 1995.

Delworth, T. L., et al., Review of simulations of climate variability and change with the GFDL R30 coupled climate model, Climate Dyn., 19, 555-574, 2002.

Dietze, H., A. Oschlies, and P. Kähler, Internal-wave induced and doublediffusive nutrient fluxes to the nutrient-consuming surface layer in the oligotrophic subtropical North Atlantic, Ocean Dynamics, in press, 2003.

Gaspar, P., Y. Gregoris, and J.-M. Lefevre, A simple eddy kinetic energy model for simulations of the oceanic vertical mixing: Tests at station Papa and Long-Term Upper Ocean Study site, J. Geophys. Res., 95, 16,179$16,193,1990$.

Gibson, J. K., et al., ECMWF Re-Analysis Project Report Series. 1. ERA Description, 72 pp., European Centre for Medium-Range Weather Forecasting, Reading, UK, 1997.

Hamilton, J. M., M. R. Lewis, and B. R. Ruddick, Vertical fluxes of nitrate associated with salt fingers in the World's Oceans, J. Geophys. Res., 94 $2137-2145,1989$

Haney, R. L., Surface thermal boundary condition for ocean circulation models, J. Phys. Oceanogr., 1, 241-248, 1971.

Jenkins, W. J., Oxygen utilization rates in North Atlantic subtropical gyre and primary production in oligotrophic systems, Nature, 300, 246-248, 1982 .

Ledwell, J. R., A. J. Watson, and C. S. Law, Evidence for slow mixing across the pycnocline from an open-ocean tracer-release experiment, Nature, 364, 701-703, 1993.

Levitus, S., and T. Boyer, World Ocean Atlas 1994, Vol. 4: Temperature. NOAA Atlas NESDIS 4, U.S. Gov. Print. Office, Washington, D.C., 99 pp., 1994.

Levitus, S., R. Burgett, and T. P. Boyer, World Ocean Atlas 1994, Vol. 3: Salinity. NOAA Atlas NESDIS 3, U.S. Gov. Print. Office, Washington, D.C., 99 pp., 1994.
Lewis, M. R., W. G. Harrison, N. S. Oakey, D. Herbert, and T. Platt, Vertical nitrate fluxes in the oligotrophic ocean, Science, 234, 870873,1986

McGillicuddy, D. J., Jr., et al., Influence of mesoscale eddies on new production in the Sargasso Sea, Nature, 394, 263-266, 1998.

Oschlies, A., Nutrient supply to the surface waters of the North Atlantic: A model study, J. Geophys. Res., 107(C5), doi:10.1029/2000JC000275, 2002a.

Oschlies, A., Can eddies make ocean deserts bloom?, Global Biogeochem. Cycles, 16, 1106, doi:10.1029/2001GB001830, 2002b.

Oschlies, A., and V. Garçon, Eddy-induced enhancement of primary production in a model of the North Atlantic Ocean, Nature, 394, 266-269, 1998.

Oschlies, A., and V. Garçon, An eddy-permitting coupled physical-biological model of the North Atlantic. Part I: Sensitivity to advection numerics and mixed layer physics, Global Biogeochem. Cycles, 13, $135-160,1999$.

Polzin, K. L., J. M. Toole, and R. W. Schmitt, Finescale parameterizations of turbulent dissipation, J. Phys. Oceanogr., 25, 306-328, 1995.

Sarmiento, J. L., T. M. C. Hughes, R. J. Stouffer, and S. Manabe, Simulated response of the ocean carbon cycle to anthropogenic climate warming, Nature, 393, 245-249, 1998.

Schmitt, R. W., The growth rate of super-critical salt fingers, Deep-Sea Res., 26, 2589-2605, 1979.

Schmitt, R. W., Form of the temperature-salinity relationship in the Central Water: Evidence for double-diffusive mixing, J. Phys. Oceanogr., 11, 1015-1026, 1981.

Schmitt, R. W., Observational and laboratory insights into salt finger convection, Progr. Oceanogr., 56, 419-433, 2003.

Schmitt, R. W., H. Perkins, J. D. Boyd, and M. C. Stalcup, C-SALT: An investigation of the thermohaline staircase in the western tropical North Atlantic, Deep-Sea Res., 34, 1655-1665, 1987.

St. Laurent, L., and R. W. Schmitt, The contribution of salt fingers to vertical mixing in the North Atlantic tracer release experiment, J. Phys. Oceanogr., 29, 1404-1424, 1999.

Washburn, L., and R. H. Käse, Double diffusion and the distribution of the density ratio in the Mediterranean waterfront southeast of the Azores, J. Phys. Oceanogr., 17, 12-25, 1987.

Zhang, J., R. W. Schmitt, and R. X. Huang, Sensitivity of the GFDL Modular Ocean Model to parameterization of double-diffusive processes, J. Phys. Oceanogr., 28, 589-605, 1998.

A. Oschlies, H. Dietze, and P. Kähler, Institut für Meereskunde, Düsternbrooker Weg 20,24105 Kiel, Germany. (aoschlies@ifm.uni-kiel.de; hdietze@ifm.uni-kiel.de; pkaehler@ifm.uni-kiel.de) 